\title{
Intoxicação aguda por diazinon em bovinos
}

\author{
Diazinon acute toxicosis in cattle \\ Márcio Botelho de Castro' ${ }^{I}$ Augusto Ricardo Coelho Moscardini ${ }^{I}$ \\ Janildo Ludolf Reis Jr. ${ }^{I}$ Ernane de Paiva Ferreira Novaes ${ }^{\text {III }}$ \\ José Renato Junqueira Borges ${ }^{\mathrm{IV}}$
}

\begin{abstract}
O presente trabalho descreve sinais muscarínicos, nicotínicos e morte em 11 de 23 bovinos adultos pulverizados com diazinon em concentração 5-6 vezes maior que a recomendada pelo fabricante. $O$ diagnóstico foi confirmado pela detecção do princípio ativo no fígado e no cérebro de um bovino.

Palavras-chave: organofosforado, diazinon, intoxicação, bovinos.

\section{ABSTRACT}

The present paper reports muscarinic and nicotinic signs and death of 11 out of 23 adult cattle treated with a pour on diazinon based product, at 5-6 times the recommended concentration by the manufacturer. The diagnosis was performed by the detection of the active principle in liver and brain of cattle.
\end{abstract}

Key words: organophosphate, diazinon, toxicosis, cattle.

O conhecimento das enfermidades do sistema nervoso dos bovinos no Brasil apresenta importância crescente desde que o país assumiu a liderança na exportação de carne e, principalmente, após o surgimento da encefalopatia espongiforme bovina (BARROS et. al., 2006). Os organofosforados (ORFs) e carbamatos incluem diversos compostos empregados como inseticidas ou anti-helmínticos, com diferentes composições químicas, com uso amplamente difundido na Agricultura e na Medicina Veterinária. Intoxicações acidentais por estes compostos em animais de importância pecuária são consideradas freqüentes e capazes de provocar sinais clínicos neurológicos (RADOSTITS et. al., 2002). O diazinon é um pesticida organofosforado, empregado com eficácia no controle de ectoparasitas como a mosca do chifre (Dermatobia irritans), em rebanhos bovinos (GUGLIELMONE et. al., 2001). Os principais efeitos tóxicos agudos dos ORFs são determinados pela inibição competitiva da enzima acetilcolinesterase (AChE), resultando no surgimento dos sinais clínicos decorrentes aos efeitos muscarínicos e nicotínicos (OSWEILER, 1998; BARROS et. al., 2006). O diazinon possui efeito tóxico mediado pelo metabólito diazinonoxon, capaz de inativar irreversivelmente a enzima AChE (POET et. al., 2004). No Brasil, mesmo sendo amplamente conhecida a toxicidade desses compostos, há poucos relatos em animais com interesse pecuário, havendo a descrição de surtos de intoxicação em bovinos por

\footnotetext{
ILaboratório de Patologia Veterinária, Faculdade de Agronomia e Medicina Veterinária (FAV), Universidade de Brasília (UnB), CP 04508, 70910-970, Brasília, DF, Brasil. E-mail: mbcastro@unb.br. Autor para correspondência.

IIPrograma de Pós-graduação em Ciência Animal, Universidade Federal de Goiás (UFG), Goiânia, GO, Brasil.

IIICurso de Medicina Veterinária, FAV, UnB, Brasília, DF, Brasil.

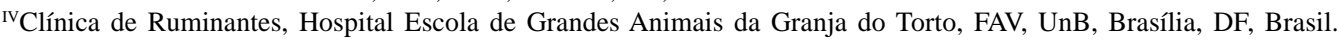


ORFs em Santa Catarina (GAVA, 2001), no Pará (BARBOSA et al., 2003) e por carbamatos no Rio Grande do Sul (SOARES et al., 2002).

Este relato descreve a mortalidade de bovinos em uma pequena propriedade rural localizada na Região Administrativa do Paranoá - DF, provocada pelo uso inadequado de inseticida à base de diazinon. Foi realizado o atendimento clínico de seis animais e a necropsia de dois bovinos adultos pela equipe do Laboratório de Patologia Veterinária e Hospital Escola de Grandes Animais - UnB. Durante levantamento epidemiológico, o proprietário informou que havia pulverizado vinte e três bovinos adultos mestiços e sete bezerros, com produto à base de diazinon, diluído em água, para controlar a infestação por carrapatos no rebanho. O inseticida foi utilizado numa diluição empírica, aproximadamente cinco a seis vezes maior que a recomendada pelo fabricante, sob a alegação de que na diluição correta, o produto apresentava-se ineficaz no controle dos carrapatos. Após o procedimento realizado no período da manhã, os bovinos adultos foram conduzidos por trajeto íngreme, ao sol, até a pastagem, distante aproximadamente 1 a $1,5 \mathrm{~km}$. Segundo o proprietário, os animais manifestaram os sinais clínicos no final da tarde daquele mesmo dia. Nenhum dos bezerros apresentou qualquer alteração; porém, permaneceram em área sombreada ao redor do estábulo utilizado na aplicação do inseticida.

Os principais sinais clínicos no exame dos bovinos foram dispnéia, sialorréia, diarréia e decúbito, observados na visita à propriedade cerca de 24 horas após a administração do produto (Tabela 1). Todos os animais afetados apresentaram incapacidade de permanecer em estação e paresia flácida (Figura 1). Cinco bovinos receberam dose única de $0,5 \mathrm{mg} \mathrm{kg}^{-1}$ de sulfato de atropina por via endovenosa, mas acabaram morrendo no dia seguinte. Um total de onze bovinos adultos apresentaram sinais de intoxicação, decúbito e morte. Com o restante do produto previamente diluído contido no pulverizador, para comprovação definitiva da toxicidade do preparado, foi banhado um bezerro com oito meses de idade, mantido ao sol e sob movimentação freqüente. $\mathrm{O}$ animal manifestou sinais após 15 minutos da exposição ao produto, com intensa salivação, timpanismo, relutância em se locomover, epífora, miose e tremores musculares. Na necropsia de dois bovinos adultos e no exame histopatológico das amostras colhidas de diversos tecidos de ambos os animais, não foram observadas alterações macro ou microscópicas dignas de nota. O princípio ativo foi detectado em amostras de fígado e córtex cerebral, de um dos bovinos, pelo método de cromatografia em camada delgada sílica gel (Centro de Assistência Toxicológica - UNESP - Botucatu, SP).

O uso inadequado dos ORFs é uma das principais causas de intoxicação nos animais pecuários, podendo ocorrer por contaminação da água, alimentos e pastagens e preparação e uso de concentrações excessivas do produto (BOERMANS et al., 1984; GAVA, 2001; RADOSTITS et al., 2002; BARROS et al., 2006). O proprietário, desconhecendo a toxicidade do diazinon, na tentativa de controlar a persistente infestação por carrapatos do rebanho, usou concentração extremamente alta do produto, o que foi determinante na intoxicação dos bovinos. Isto pôde

Tabela 1 - Sinais clínicos apresentados por seis bovinos intoxicados acidentalmente por diazinon.

\begin{tabular}{|c|c|c|c|c|c|c|}
\hline Sinais clínicos & Bovino 1 & Bovino 2 & Bovino 3 & Bovino 4 & Bovino 5 & Bovino 6 \\
\hline Decúbito external & +++ & - & - & $+++^{\mathrm{a}}$ & +++ & - \\
\hline Decúbito lateral & - & +++ & +++ & - & - & +++ \\
\hline Paresia flácida & +++ & +++ & +++ & +++ & +++ & +++ \\
\hline Tremores musculares & - & - & - & + & + & ++ \\
\hline Opistótono & - & ++ & ++ & - & - & + \\
\hline Dispnéia & + & +++ & ++ & - & - & +++ \\
\hline Bradicardia & $+^{\mathrm{b}}$ & - & - & $+^{c}$ & - & - \\
\hline Epífora & +++ & + & - & - & - & - \\
\hline Miose & +++ & ++ & ++ & - & - & - \\
\hline Sialorréia & ++ & ++ & ++ & - & - & - \\
\hline Diarréia & ++ & +++ & + & - & - & - \\
\hline Timpanismo & - & - & - & - & - & ++ \\
\hline
\end{tabular}

+++ sinal acentuado, ++ sinal moderado, + sinal discreto e - sinal ausente.

$+++{ }^{\mathrm{a}}$ com membros pélvicos esticados em abdução.

$+{ }^{\mathrm{b}} 48$ batimentos por minuto.

$+{ }^{\mathrm{C}} 52$ batimentos por minuto. 


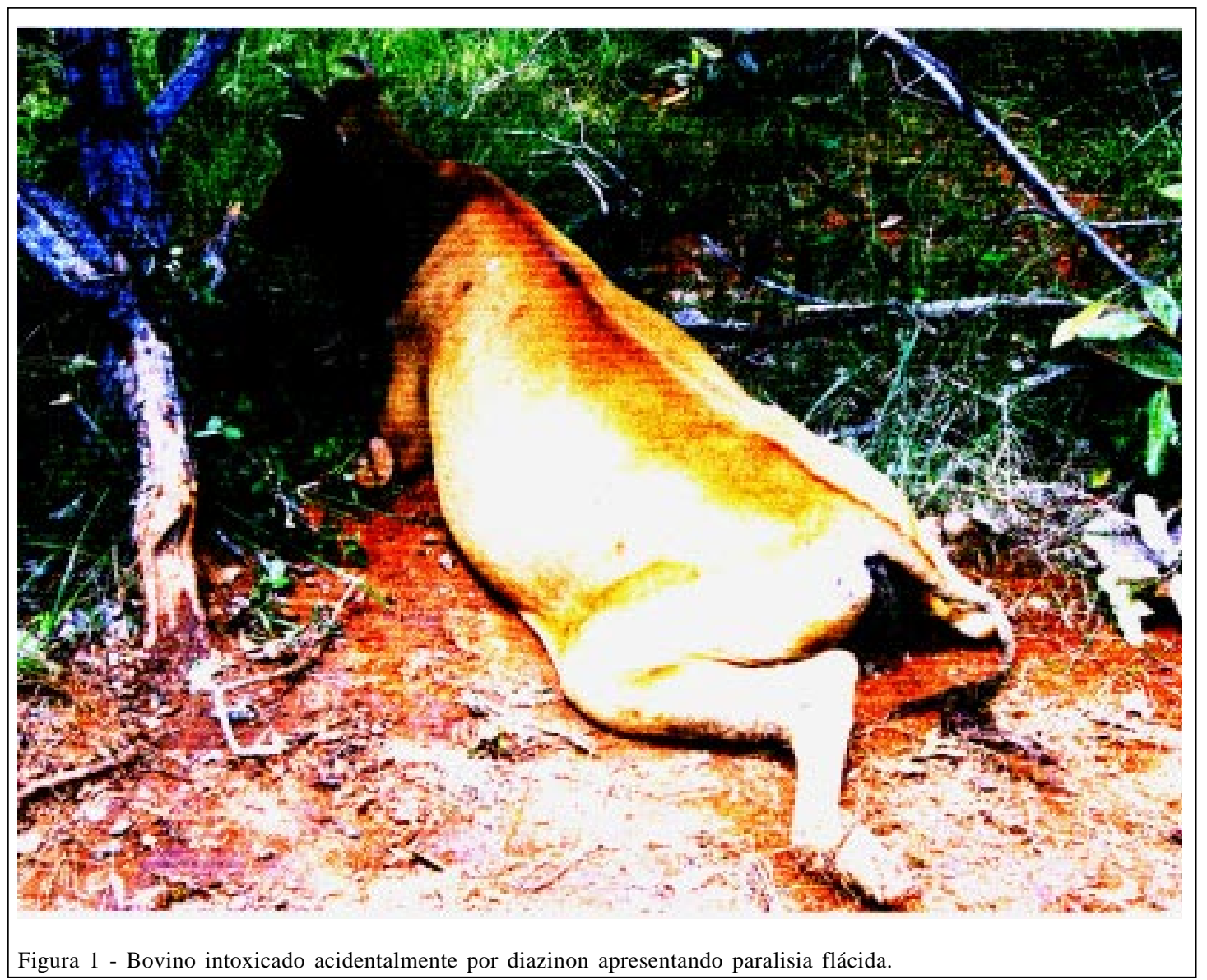

ser demonstrado experimentalmente num bezerro que rapidamente manifestou sintomas da intoxicação após ser pulverizado com o produto restante. O diazinon pode apresentar resultados insatisfatórios no controle do carrapato Boophilus microplus, devido à freqüente resistência do parasita frente ao inseticida (LI et al., 2003). Outro fator importante, que possivelmente contribuiu para a ocorrência de toxicidade, foi o aumento na absorção pela pele do princípio, devido ao esforço físico necessário para atingir a área de pastagem em trajeto bastante íngreme e à exposição intensa ao sol (OSWEILER, 1998; RADOSTITS et al., 2002). Animais privados de água, jovens, zebus e seus cruzamentos são considerados mais susceptíveis à intoxicação por ORFs (RADOSTITS et al., 2002; BARROS et al., 2006). Neste caso, possivelmente os bezerros não foram afetados por permanecerem em piquete à sombra, próximo ao local de aplicação do inseticida.

Um achado importante a ser observado foi o surgimento de sinais clínicos em 47,82\% dos animais adultos, com letalidade de 100\%. Surtos de intoxicação acidental por ORFs em rebanhos bovinos vêm sendo descritos com taxa de mortalidade variando entre 31 a $53,8 \%$, com o óbito de aproximadamente $100 \%$ dos bovinos que apresentaram decúbito, mesmo após o tratamento com sulfato de atropina (PUGH, 1975; KHAN, 2001).

Dentre os sinais clínicos observados, aquele que mais chamou a atenção foi a paralisia flácida e o decúbito em todos os animais afetados. A dispnéia foi um achado freqüente, porém não foram observados estertores ruidosos típicos como previamente descrito (BOERMANS et al., 1984; GAVA, 2001). Os animais, ao momento do exame, estavam com grau considerável de desidratação, há várias horas expostos ao sol e privados de água. Isto possivelmente tenha contribuído para reduzir a intensidade na manifestação dos sinais muscarínicos (salivação, secreção em vias aéreas e diarréia). Mesmo os sinais muscarínicos sendo mais comumente observados em ruminantes, sinais nicotínicos como paralisia flácida, opistótono, tremores e fraqueza muscular podem ser observados (RADOSTITS et al., 2002). O fato de os animais terem

Ciência Rural, v.37, n.5, set-out, 2007. 
sido examinados somente 12 a 18 horas após encontrados em decúbito pode ter contribuído para a observação mais proeminente dos sinais de natureza nicotínica.

Durante surtos de mortalidade em bovinos com sinais clínicos neurológicos, a intoxicação por compostos ORFs deve ser considerada e incluída no diagnóstico diferencial. É importante que o uso desses produtos seja criterioso, especialmente devido ao crescente aumento da resistência dos ectoparasitas aos princípios ativos.

\section{REFERÊNCIAS}

BARBOSA, J.D. et al. Intoxicação por organofosforados em rebanho de bovinos. In: CONGRESSO LATINO AMERICANO DE BUIATRIA, 11., 2003, Salvador, BA. Anais... Salvador: Congresso Latino Americano de Buiatria, 2003. p.21.

BARROS, C.S.L. et al. Doenças do sistema nervoso de bovinos no Brasil. São Paulo: Coleção Vallée, 2006. 207p.

BOERMANS, H.J. et al. Terbufos poisoning in a dairy herd. Canadian Veterinary Journal, Guelph, v.25, p.335-338, 1984.

GAVA, A. Intoxicação por organofosforados e carbamatos. In: RIET-CORREA et al. Doenças de ruminantes e equinos. 2.ed. São Paulo: Varela, 2001. v.2, p.208-211.

GUGLIELMONE, A.A. et al. Toxicity of cypermethrin and diazinon to Haematobia irritans (Diptera: Muscidae) in its
American range. Veterinary Parasitology, Amsterdam, v.101, p.67-73, 2001.

KHAN, O. Organophosphate poisoning in a group of replacement heifers and dry cows. Canadian Veterinary Journal, Guelph, v.42, p.561-563, 2001.

LI, A.Y. et al. Resistance to coumaphos and diazinon in Boophilus microplus (Acari: Ixodidae) and evidence for involvement of an oxidative detoxication mechanism. Journal of Medical Entomology, Honolulu, v.40, p.482-490, 2003.

OSWEILER, G.D. Inseticidas e Moluscicidas. In: Toxicologia veterinária. Porto Alegre: Editora Artes Médicas Sul, 1998. p.259-282.

POET, T.S. et al. Physiologically based pharmacokinetic/ pharmacodynamic model for the organophosphorus pesticide diazinon. Neurotoxicology, Amsterdam, v.25, p.1013-1030, 2004.

PUGH, W.S. An outbreak of organophosphate poisoning (Thimet) in cattle. Canadian Veterinary Journal, Guelph, v.16, p.56-58, 1975.

SOARES, A.C. et al. Intoxicação acidental por carbamatos em bovinos de corte no sul do Brasil. In: CONGRESSO BRASILEIRO DE MEDICINA VETERINÁRIA, 29, 2002, Gramado, RS. Anais... Gramado: Combravet, 2002. p.CCP-714.

RADOSTITS, O.M. et. al. Compostos organofosforados e carbamatos (organofosfatos). In: Clínica veterinária. 9.ed. Rio de Janeiro: Guanabara Koogan, 2002. p.1456-1459. 